\title{
RESILIENSI KELUARGA
}

\section{PADA KELUARGA YANG MEMILIKI ANAK AUTIS}

\author{
Eunike Apostelina \\ Jurusan Psikologi, Fakultas Ilmu Pendidikan, Universitas Negeri Jakarta \\ Jalan Rawamangun Muka Jakarta Timur 13220, DKI Jakarta
}

Email: apostelina@gmail.com

\begin{abstract}
This study aimed to determine the family resilience in families who have children with autism based on seven dimensions: stressors, strain, relative and friend support, social support, resilience, coping-coherence, and the distress raised by McCubbin, et al.

The method used in this research is descriptive quantitative method equipped with qualitative methods. Participants in this study consisted of 32 families with an autistic child to fill the scale of family resilience and for qualitative consisted of three families with an autistic child. Quantitative determination of samples was selected using purposive sampling techniques. Qualitative determination of the sample was selected using the sampling technique with a maximum variation. Data obtained with the scale of family resilience raised by McCubbin using the Likert scale models. For the qualitative data obtained through interviews, observation, field notes and open questionnaires.

The results of quantitative research shows that family resilience in families with an autistic child classified in the category of medium based on the seven dimensions proposed by McCubbin and McCubbin. There are 21 (66\%) families who are at medium stressor category, 28 (87.5\%) families included in the category of medium strains, 25 (78.1\%) fall into the category of families have relatives and friends who support medium, 24 families (75\%) included in the category of having social support medium, 15 families (46.9\%) fall into the category of families who have family resilience medium, 23 families (71.9\%) having a coping-coherence of the medium, and 28 families (87.5\%) having a medium distress. The results of qualitative research showed that there were two families who have low family resilience and belonging to a family of medium. These three families have been able to fight for children's education, although not yet optimal. The three families particularly difficult to get social support from neighbors / friends around. This suggests that families with an autistic child are experiencing difficult and tend to feel protective factor in the risk factors through the process of life, making it difficult to achieve adaptation._These three families have a tendency to get family distress.
\end{abstract}

Keywords: family resilience, family, Autism. 


\section{Pendahuluan}

Autisme dan berbagai gejalanya menimbulkan serta memberikan dampak stres pada keluarga yang memiliki anak autis. Keluarga akan mengalami banyak perubahan. Perubahan yang terjadi pada keluarga berkemungkinan menyebabkan keluarga berada pada situasi krisis.

Hal ini menyebabkan orangtua dan saudara kandung membuat perubahan dan berbagai pengorbanan dalam fungsi keluarga secara optimal. Sebagian besar orangtua menginginkan anak mereka memiliki pertumbuhan dan perkembangan yang normal, namun pada kenyataannya ada dari mereka yang dikaruniai anak autis untuk mereka rawat dan mereka didik.

Diagnosis autis terhadap anak merupakan stressor utama yang dirasakan keluarga. Autisme tidak dapat dicegah karena penyebab belum diketahui pasti sampai saat ini. Selain stressor utama, keluarga juga merasakan beberapa stressor dan strain lain yang menyebabkan terjadi akumulasi dari peristiwa yang menekan. Interaksi akumulasi dari peristiwa hidup ini menyebabkan keluarga berada dalam krisis.

Krisis tersebut dapat berupa penolakan terhadap anak-anak autis yang terlihat ketika mereka sulit diterima untuk belajar di sekolahsekolah umum sebagaimana anak-anak lainnya. Selain itu krisis juga dapat berupa emosi yang terkait dengan membesarkan/merawat anak autis mencakup frustasi, kecemasan, keresahan, terkejut,

\section{A. Resiliensi Keluarga}

\section{a.1 Definisi Resiliensi Keluarga}

Konsep resiliensi keluarga berakar dari pemahaman mengenai resiliensi individu. Resiliensi merupakan proses adaptasi secara baik dalam menghadapi kemalangan, trauma, tragedi, ancaman, atau bahkan sumber stres yang signifikan. Konsep resiliensi tidak hanya mencakup kemampuan untuk bertahan tetapi juga bangkit kembali dari krisis. Secara umum penelitian resiliensi berfokus kepada resiliensi individu, dengan perhatian khusus kepada anak-anak yang berada dalam bahaya hingga mengalami kemalangan. Walgnild dan young mengatakan bahwa resiliensi adalah kemampuan untuk mengatasi perubahan atau kemalangan. Berakar dari ulasan mengenai resiliensi terhadap ketidakberdayaan, marah, kesedihan, kekesalan, permasalahan keuangan (financial strain), beban dalam mengasuh, kekacauan dari aktivitas yang telah direncanakan, keterbatasan dalam berwisata, perubahan rencana dalam waktu yang singkat, dan fokus keluarga hanya pada tujuan jangka pendek dibandingkan dengan tujuan jangka panjang.

Agar bisa beradaptasi dengan baik keluarga harus bisa menggunakan sumber daya yang dimilikinya. Sumber daya itu dapat berupa dukungan sosial yang didapat dari kerabat dan teman serta komunitas dan sumber daya sistem keluarga yang meliputi kemampuan ketahanan keluarga. Sumber daya yang dimiliki keluarga akan membantu keluarga untuk beradaptasi dengan masalah yang dihadapinya. Keluarga yang memiliki sumber daya yang lebih banyak akan lebih mudah beradaptasi dengan peristiwa kehidupan yang menekan.

Keluarga yang dapat beradaptasi dengan sukses akan mencapai keseimbangan dalam keluarga. Keluarga tersebut dapat dikatakan resilien. Untuk mengetahui resiliensi keluarga pada keluarga yang memiliki anak autis, perlu dilihat bagaimana stressor dan strain yang dihadapi keluarga, bagaimana dukungan yang diterima keluarga, bagaimana karaterisktik ketahanan keluarga sebagai sumber daya sistem yang dimiliki keluarga, bagimana keluarga mendefinisikan serta menilai peristiwa yang dihadapinya, serta peristiwa distress yang dirasakan keluarga.

individu, muncullah istilah resiliensi keluarga (family resicilence) yang menyatakan kemampuan keluarga untuk melanjutkan hidup setelah ditimpa kemalangan atau tekanan yang berat.

Resiliensi adalah kemampuan bangkit kembali dari masalah sehingga menjadi lebih kuat dan lebih pandai dalam menghadapi masalah. Definisi ini mengisyaratkan bahwa resiliensi melibatkan dua fenomena, yaitu yang pertama mengalami masalah yang juga berarti dalam keadaan resiko tinggi dan yang kedua mampu untuk mencegah konsekuensi negatif yang berhubungan dengan resiko tersebut, juga memacu pertumbuhan. Hawley \& De Haan menyatakan bahwa proses resiliensi sebagai interaksi antara faktor risiko dan faktor protektif. 
Faktor protektif dapat dianggap kuat, berinteraksi dengan faktor risiko, mengurangi dampak negatif dari risiko. Model ini juga mengatakan bahwa resiliensi tidak hanya bangkit kembali dan menjadi kuat tetapi juga adanya kekuatan yang membantu seseorang untuk bertahan dari masalah mereka serta tumbuh menjadi manusia yang lebih kuat.

Resiliensi bukanlah hal yang dibicarakan fokus pada individu saja melainkan sebuah proses interaksional antara karakteristik individual dan lingkungan. Resiliensi juga dimiliki oleh keluarga sebagai sebuah satu kesatuan. Resiliensi keluarga adalah proses adaptasi dan coping dalam keluarga sebagai sebuah unit fungsional. Resiliensi melibatkan proses dinamis yang membantu beradaptasi dalam masalah yang signifikan. Kekuatan dan sumber daya inilah yang memungkinkan individu serta keluarga untuk sukses menghadapi krisis dan masalah yang persisten. Selain itu, kekuatan dan sumber daya yang dimiliki dapat memulihkan dan bertumbuh dari pengalaman yang tidak menyenangkan. Konsep resiliensi keluarga meluas dari yang tadinya hanya melihat individu (anggota keluarga) sebagai sumber daya potensial untuk resiliensi individu menjadi fokus pada risiko dan resiliensi pada keluarga sebagai sebuah unit fungsional.

Boss mengatakan bahwa resiliensi keluarga melibatkan potensi perubahan dan pertumbuhan baik secara personal maupun relasional yang dapat membantu keluar dari masalah. Keluarga dapat menjadi lebih kuat dan lebih pandai ketika berhadapan dengan masalah di masa yang akan datang. Adanya masalah dapat menjadi kesempatan bagi keluarga untuk menilai kembali prioritas, menstimulasi hubungan yang lebih baik dan tujuan hidup keluarga. Anggota keluarga mungkin dapat menemukan atau mengembangkan hikmah dan kemampuan baru.

Pada penelitian ini akan digunakan definsi dari McCubbin dan McCubbin. McCubbin dan McCubbin mendefinisikan resiliensi keluarga sebagai:

"the positive behavioral patterns and functional competence individual and the family unit demonstrate under stressful or adverse circumstances, which determine the family's ability to recover by maintaining its integrity as a unit while insuring, and where necessary restoring, the well-being of family members, and the family unit as a whole"

McCubbin dan McCubbin mengatakan bahwa resiliensi keluarga merupakan gabungan antara pola tingkah laku positif dan kompetensi fungsional yang dipunyai masing-masing individu dalam keluarga dan unit keluarga secara keseluruhan. Tingkah laku positif dan kompetensi individual ini diperlukan dalam bereaksi terhadap lingkungan yang menekan dan merugikan (seperti peristiwa hidup yang signifikan). Selain itu juga menentukan kemampuan keluarga tersebut untuk pulih dengan cara mempertahankan integritasnya sebagai sebuah kesatuan namun dengan tetap mempertahankan dan memperbaiki kesejahteraan anggota keluarga dan unit keluarga secara keseluruhan.

\section{a.2 The Resiliency Model of Family Stress, Adjustment, and Adaptation}

Kerangka teoritis yang digunakan adalah Model Resiliensi dari Stress, Penyesuaian, dan Adaptasi Keluarga (The Resiliency Model of Family Stress, Adjustment, and Adaptation). Hal ini dikarenakan model ini sesuai untuk mengidentifikasi peristiwa hidup yang signifikan dan proses spesifik yang memungkinkan keluarga untuk bisa pulih dan beradaptasi dengan sukses dan bisa menjadi resilien.

\section{a.3 Sejarah Perkembangan Model Resiliensi Keluarga}

Dasar utama pengembangan model ini adalah teori stres keluarga yang mengacu kepada model ABC-X dari Rueben Hills. Model ini dilatarbelakangi kehidupan keluarga setelah perang dunia kedua. Melalui model ini, Hills menjelaskan bagaimana keluarga bisa beradaptasi dengan krisis yang disebabkan oleh perang. Setiap huruf dari model ABC-X merepresentasikan proses spesifik yang dialami keluarga ketika dihadapkan kepada sebuah stressor. Menurut Hills, situasi yang menekan adalah sebuah peristiwa yang bisa menyebabkan gangguan dari kehidupan normal keluarga yang mengharuskan keluarga untuk beradaptasi. Huruf A merepresentasikan peristiwa yang menekan (stressor) yang mempunyai potensi untuk menyebabkan penderitaan pada keluarga. 
Dalam penelitian ini, situasi menekan yang dihadapi keluarga adalah diagnosis autis, proses merawat dan mendidik anak autis yang harus di jalani. Huruf B merepresentasikan sumber daya atau kemampuan keluarga dalam beradaptasi dengan situasi yang menekan. Huruf B berupa dukungan sosial dan kekuatan personal yang dimiliki keluarga. Huruf $\mathrm{C}$ merepresentasikan cara keluarga memandang peristiwa yang menekan tersebut, termasuk didalamnya bagaimana keluarga mendefinisikan peristiwa kehidupan itu. Huruf X mewakili derajat dari krisis yang dialami keluarga. Berdasarkan model ini keluarga dengan sumber daya yang terbatas dan memiliki pandangan negatif terhadap situasi akan mengalami krisis yang lebih berat dari pada keluarga lainnya yang dihadapkan pada peristiwa menekan yang sama.

Kritik diajukan oleh McCubbin dan Peterson terhadap model ABC-X dari Hills. Model ABC-X dianggap hanya menjelaskan efek situasi menekan terhadap keluarga tetapi tidak menjelaskan bagaimana keluarga bisa menyesuaikan dan beradaptasi terhadap situasi tersebut. Tindak lanjut dari kritikan ini, McCubbin dan Peterson mengajukan sebuah model untuk menyempurnakan model ABC-X, yaitu model penyesuaian dan adaptasi double ABC-X. Model double $A B C-X$ memfokuskan terhadap faktor-faktor seperti kemampuan coping dan dukungan sosial keluarga yang menfasilitasi keluarga dalam beradaptasi dengan situasi menekan.

\section{a.4 Dimensi Resiliensi Keluarga}

Menggunakan tujuh dimensi yang akan diteliti untuk menjawab pertanyaan penelitian pada penelitian ini. Pemilihan tujuh dimensi ini berdasarkan penyataan yang menyatakan bahwa tujuh dimensi ini adalah salah satu pilihan dimensi utama yang digunakan untuk melihat proses adaptasi keluarga. Tujuh dimensi tersebut adalah dua dimensi yang mempengaruhi pile up demands yaitu family stressor dan family strain, dua dimensi yang mengukur social support yaitu dukungan kerabat dan teman serta dukungan komunitas, satu dimensi mengukur family system resources yaitu family hardiness, satu dimensi yang mengukur family appraisal yaitu family coherence, serta satu dimensi mengukur adanya kecenderungan maladaptasi yaitu dimensi family distress.

\section{B. Autisme b.1 Pengertian Autisme}

Istilah "autisme" pertama kali diperkenalkan pada tahun 1943 oleh Leo Kanner. Dia menulis makalah yang menjabarkan gejala-gejala "aneh" yang ia temukan pada sebelas orang anak yang menjadi pasiennya. Ia melihat banyak sekali persamaan gejala pada anak-anak tersebut, namun yang sangat menonjol adalah anak ini sangat asyik dengan dirinya sendiri, seolah-olah ia hidup dalam dunianya sendiri. Istilah autisme jika diartikan secara singkat adalah orang yang hidup dalam dunianya sendiri.

Secara etimologis kata "autisme" berasal dari kata "auto" dan "isme". Auto artinya diri sendiri dan isme berarti suatu aliran/paham. Dengan demikian autisme diartikan sebagai suatu paham yang hanya tertarik pada dunianya (diri) sendiri. Perilakunya timbul semata-mata karena dorongan dari dalam dirinya. Penyandang autisme seakanakan tidak peduli dengan stimulus-stimulus yang datang dari orang lain, ada gangguan komunikasi.

Penyandang autisme memiliki gangguan pada interaksi sosial, komunikasi verbal maupun nonverbal, imajinasi, pola perilaku repetitif dan resistensi terhadap perubahan pada rutinitas. Menurut Sunartini menjelaskan pula bahwa autistik diartikan sebagai gangguan perkembangan pervasif yang ditandai oleh adanya abnormalitas dan kelainan yang muncul sebelum anak berusia tiga tahun. Fungsi yang abnormal tersebut adalah interaksi sosial, komunikasi, dan perilaku yang terbatas dan terulang. Sehingga mereka tidak mampu mengekspresikan perasaan maupun keinginan mereka yang mengakibatkan terganggunya proses sosialisasi dengan orang lain.

Beberapa ahli juga menemukan bahwa anak autistik mengalami beberapa gangguan antara lain pada cerebellum yang berfungsi dalam proses sensorik, mengingat, kemampuan bahasa dan perhatian. Gangguan juga terjadi pada sistem limbik yang merupakan pusat emosi sehingga penderita kesulitan mengendalikan emosi, mudah mengamuk, marah, agresif, menangis, takut pada hal-hal tertentu dan mendadak tertawa. Perhatiannya terhadap lingkungan terhambat karena adanya gangguan pada lobus parietallis. 
Autisme bukanlah penyakit mental maupun psikosis (kejiwaan). Sebagian besar penyandang autisme juga mengalami cacat mental, tapi masalah mereka dengan perkembangan komunikasi, perilaku sosial dan imajinasi tidak dapat dijelaskan hanya dengan istilah keterbelakangan mental. Autistik dapat terjadi pada setiap anak tidak memandang lapisan sosial ekonomi, tingkat pendidikan orangtua, ras, etnik maupun agama.

\section{b.2 Penyebab Autisme}

Sampai saat ini masih belum diketahui dengan pasti penyebab dari autistik. Berbagai penelitian telah dilakukan untuk mencari penyebabnya. Akan tetapi pemeriksaan dan pembahasan secara ilmiah baru dimulai pada tahun 1943 oleh Leo Kanner yang mengamati bahwa sejak awal terdapat suatu kesendirian autistik ekstrem yang kapanpun memungkinkan, tidak memedulikan, mengabaikan, menutup diri dari segala hal yang berasal dari luar dirinya. Ada beberapa teori yang sempat berkembang di masyarakat tapi tidak bertahan lama karena tidak dapat dibuktikan lagi seiring perkembangan zaman.

Meurice menegaskan bahwa autistik merupakan gangguan perkembangan pervasif yang disebabkan oleh gangguan biologi di otak, bukan gangguan emosi akibat perilaku orangtua atau keluarga. Pada tahun 1990, Margareth Bauman dari Harvard Medical School dan Erick menemukan bahwa adanya kelainan neuron-anatomy pada beberapa tempat di otak para penyandang autisme. Dengan melakukan pemerikasaan Magnetic Resonance Imaging (MRI) Erick menemukan adanya pengecilan cerebellum (otak kecil), terutama pada lobus VI-VII. Penemuan ini ditunjang oleh hasil otopsi oleh Margareth yang menemukan adanya kelainan struktur pada pusat emosi. Gangguan neuro-anatomi ini disertai juga gangguan bio-kimia otak.

Autistik diduga merupakan gangguan dengan penyebab multifaktorial, meliputi penyebab genetik atau biologik dan penyebab lingkungan. Beberapa penelitian menunjukkan betapa banyak gangguan metabolisme yang diderita anak autistik.

Meskipun belum ada kepastian penyebab autis, namun penelitian-penelitian dan pendapatpendapat sehubungan dengan faktor penyebab terjadinya anak autis dapat disimpulkan bahwa penyebab autistik diduga dari multifaktorial. Meliputi penyebab genetik atau biologik dan penyebab lingkungan. Kelainan organik yang terbanyak ditemukan pada cerebellum, hipokampus dan amigdala di lobus frontalis, dan batang otak. Berbagai faktor lingkungan akan menyebabkan munculnya gejala autistik pada anak yang sudah mempunyai predisposisi genetik.

\section{b.3 Ciri-ciri Autisme}

Gangguan autistik dalam DSM-IV (Diagnostic Statistical Manual) adalah sebagai berikut. Terdapat paling sedikit enam pokok dari kelompok 1, 2 dan 3 yang meliputi paling sedikit dua pokok dari kelompok 1, paling sedikit satu pokok dari kelompok 2 dan paling sedikit satu pokok dari kelompok 3 .

1) Gangguan kualitatif dalam interaksi sosial yang ditunjukkan oleh paling sedikit dua di antara yang berikut ini:

a) Ciri gangguan yang jelas dalam penggunaan berbagai perilaku nonverbal (bukan lisan) seperti kontak mata, ekspresi wajah, gesture, dan gerak isyarat untuk melakukan interaksi sosial.

b) Ketidakmampuan mengembangkan hubungan pertemanan sebaya yang sesuai dengan tingkat perkembangannya.

c) Ketidakmampuan turut merasakan kegembiraan orang lain.

d) Kekurangmampuan dalam berhubungan emosional secara timbal balik dengan orang lain.

2) Gangguan kualitatif dalam berkomunikasi yang ditunjukkan oleh paling sedikit satu dari yang berikut ini:

a) Keterlambatan atau kekurangan menyeluruh dalam berbahasa lisan (tidak disertai usaha untuk mengimbanginya dengan penggunaan gesture atau mimik muka sebagai cara alternatif dalam berkomunikas).

b) Ciri gangguan yang jelas pada kemampuan untuk memulai atau melanjutkan pembicaraan dengan orang lain meskipun dalam percakapan sederhana. 
c) Penggunaan bahasa-bahasa yang repetitif (diulang-ulang) atau stereotip (meniru-niru) atau bersifat idionsinktratik (aneh).

d) Kurang beragamnya spontanitas dalam permainan pura-pura atau meniru orang lain yang sesuai dengan tingkat perkembangannya.

3) Pola minat perilaku yang terbatas, repetitif, dan stereotip seperti yang ditunjukkan oleh paling tidak satu dari yang berikut ini:

a) Meliputi keasyikkan dengan satu atau lebih pola minat yang terbatas atau stereotip yang bersifat abnormal baik dalam intensitas maupun fokus.

b) Kepatuhan yang tampaknya didorong oleh rutinitas atau ritual spesifik (kebiasaan tertentu) yang nonfungsional (tidak berhubungan dengan fungsi).

\section{Metode Penelitian}

Penelitian ini dilakukan di Yayasan Cagar Rumah Autis Bekasi, cabang Bogor, dan cabang Depok serta di Yayasan Bimatera Jakarta Timur. Metode penelitian yang digunakan adalah metode campuran sekuensial / bertahap (sequential mixed methods) merupakan prosedur-prosedur dimana di dalamnya peneliti berusaha menggabungkan atau memperluas penemuan-penemuannya yang diperoleh dari satu metode dengan penemuanpenemuannya dari metode lainPenelitian ini bertujuan untuk mengetahui resiliensi keluarga pada keluarga yang memiliki anak autis.

Populasi dalam penelitian ini adalah keluarga yang memiliki anak berkebutuhan khusus autis yang menjalani terapi di Rumah Autis Bekasi, cabang Bogor dan cabang Depok serta Yayasan Bimatera Jakarta Timur berjumlah 88 keluarga yang memiliki anak autis. Teknik pemilihan sampel yang digunakan dalam penelitian ini bersifat nonprobability sampling. Pada penelitian ini tidak semua individu dalam populasi memiliki kesempatan yang sama untuk menjadi sampel. Cara pengambilan sampel yaitu dengan purposive sampling. Tehnik ini melakukan pengambilan sampel secara sengaja sesuai dengan persyaratan sampel yang diperlukan. Penentuan sampel pada penelitian ini disesuaikan dengan tujuan yaitu mendapatkan deskripsi resiliensi keluarga yang memiliki anak autis. Untuk memperoleh data c) Perilaku gerakan stereotip dan repetitif (seperti terus menerus membuka-tutup genggaman, memuntir jari atau tangan atau menggerakkan tubuh dengan cara yang kompleks).

d) Keasyikan yang terus-menerus terhadap bagian-bagian dari sebuah benda.

Perkembangan abnormal atau terganggu sebelum usia 3 tahun seperti yang ditunjukkan oleh keterlambatan atau fungsi yang abnormal pada paling sedikit satu dari bidang-bidang berikut ini: (1) interaksi sosial, bahasa yang digunakan dalam perkembangan sosial, (2) bahasa yang digunakan dalam komunikasi sosial, atau (3) permainan simbolik atau imajinatif.

kuantitatif menggunakan purposive sampling, yaitu keluarga yang sesuai dengan karakteristik tujuan.

Untuk data kualitatif dilakukan dengan pengambilan sampel dengan variasi maksimum. Poerwandari mengatakan, bahwa pengambilan ini dilakukan bila subjek penelitian menampilkan banyak variasi, dan penelitian bertujuan menangkap dan menjelaskan tema-tema sentral yang tertampilkan sebagai akibat keluasan cakupan (variasi) partisipan penelitian. Keterwakilan semua variasi penting, dan pendekatan sampel variasi maksimum justru mencoba memanfaatkan adanya perbedaan-perbedaan yang ada untuk menampilkan kekayaan data.

Patton dalam Poerwandari mengatakan bahwa bila penentuan sampel dilakukan dengan baik, temuan diharapkan dapat menampilkan: (1) deskripsi yang berkualitas dan mendetail dari tiap kasus, dengan mendokumentasikan keunikan masing-masing kasus; (2) pola-pola yang tampil dari kasus yang berbeda-beda, sebagai konsekuensi dari heterogenitas sampel. Variasi pada penelitian ini adalah jumlah keluarga, jenis autisme dan usia anak yang dapat mempengaruhi resiliensi keluarga.

Tehnik pengumpulan data awal dilakukan secara kuantitatif dengan menyebarkan skala psikologi. Selanjutnya dilakukan pengambilan data secara kualitatif. Pendekatan penelitian ini dilakukan karena permasalahan penelitian dilihat 
sebagai realitas sosial yang memerlukan eksplorasi mendalam. Penelitian kualitatif adalah penelitian yang menekankan pada kualitas atau hal terpenting dari suatu fenomena. Suatu penelitian kualitatif dieksplorasi dan diperdalam dari suatu fenomena sosial yang terdiri atas pelaku, kejadian, tempat, dan waktu. Data kualitatif diperoleh melalui wawancara mendalam pada keluarga yang memiliki anak autis. Keluarga yang diwawancara adalah keluarga yang ikut mengisi kuesioner pada data kuantitatif. Jumlah keluarga yang akan diwawancara adalah tiga keluarga.

Instrumen penelitian yang akan digunakan dalam pengambilan data terbagi atas instrumen penelitian kuantitatif dan instrumen penelitian kualitatif. Instrumen kuantitatif yang digunakan adalah kuesioner yang dibuat oleh McCubbin dan McCubbin.

Untuk instrumen kualitatif, metode pengambilan data yang digunakan ialah wawancara, observasi, catatan lapangan dan dokumen berisi kisah beberapa orangtua yang memiliki anak autis. Tujuan dari metode wawancara ini menurut Banister dkk ialah untuk memperoleh pengetahuan tentang makna-makna subjektif yang dipahami individu berkenaan dengan topik yang diteliti, dan bermaksud melakukan eksplorasi terhadap isu tersebut, suatu hal yang tidak dapat dilakukan melalui pendekatan lain. Observasi dilakukan karena merupakan metode pengumpulan data esensial dalam penelitian, apalagi penelitian dengan pendekatan kualitatif.

Teknik analisa data yang dilakukan untuk mengatasi data pada penelitian ini adalah teknik eksplanatoris sekuensial. Merupakan strategi yang lebih condong pada proses kuantitatif. Teknik ini diterapkan dengan pengumpulan dan analisisi data kuantitatif pada tahap pertama yang diikuti oleh pengumpulan dan analisis data kualitatif pada tahap kedua. Rancangan eksplanatoris sekuensial biasanya digunakan untuk menjelaskan dan menginterpretasikan hasil-hasil kuantitatif berdasarkan hasil pengumpulan dan analisis data kualitatif. Menurut Morse, 1991, rancangan ini

\section{Hasil \& Diskusi}

Berikut adalah hasil dan diskusi dari penelitian mengenai resiliensi keluarga pada keluarga yang memiliki anak autis. Berdasarkan skor resiliensi secara khusus berguna ketika muncul hasil-hasil yang tidak diharapkan dari penelitian kuantitatif. Sifat keterusterangan (straightforwarad) dari rancangan ini merupakan salah satu kekuatan utamanya. Berikut adalah teknik analisis data kuantitatif dan kualitatif:

1. Statistik deskriptif data (mencari mean, median, modus, range, varian, nilai maksimal, nilai minimal, dan standar deviasi)

2. Pada penelitian kuantitatif ini, digunakan patokan standar yang ditetapkan oleh McCubbin dkk. Kategori sedang apabila nilai skor resiliensi terletak pada rentang 1SD diatas dan dibawah mean. Kategori rendah apabila skor resiliensi lebih kecil dari 1SD dibawah mean. Kategori tinggi apabila nilai skor resiliensi lebih besar dari 1SD diatas mean.Untuk menentukan kategorisasi skor keseluruhan aspek, ketentuan yang digunakan adalah sebagai berikut :

\begin{tabular}{ll}
\hline Tinggi & $=\mathrm{X}>($ Mean + 1SD $)$ \\
Rendah & $=\mathrm{X}<($ Mean -1 SD) \\
Medium (Sedang) & $=$ Rendah $\leq \mathrm{X} \leq$ Tinggi \\
\hline
\end{tabular}

3. Pembacaan koding transkrip verbatim wawancara:

W1.ME.P.26 Juni 2012. Lamp. 6 Hal: 155, 166-168

Keterangan

W1.ME : Wawancara pertama pada subjek

ME

26 Juni 2012 : tanggal wawancara

Lamp. 6 Hal 155 : transkrip berada di lampiran 6 halaman 155

166-168 : kutipan berada di baris 166 sampai dengan 168 pada transkrip.

\section{Triangulasi Data}

Triangulasi yang dilakukan pada penelitian kualitatif ini adalah triangulasi data. Menurut Paton dalam penelitian kualitatif oleh Burhan, hal ini dilakukan untuk membangdingkan dan mengecek bait derajat kepercayaan suatu informasi yang diperoleh melalui waktu dan cara yang berbeda dalam metode kualitatif.

keluarga yang diperoleh, maka didapatkan data sebagai berikut : 
Distribusi Frekuensi Skor Resiliensi Keluarga

\begin{tabular}{rccc}
\hline $\begin{array}{l}\text { No } \\
\cdot\end{array}$ & $\begin{array}{c}\text { Interval } \\
\text { Skor }\end{array}$ & Frek (f) & $\begin{array}{l}\text { Persentase } \\
(\%)\end{array}$ \\
\hline $\mathbf{1}$ & $56-66$ & 2 & $6,2 \%$ \\
$\mathbf{2}$ & $67-77$ & 1 & $3,1 \%$ \\
$\mathbf{3}$ & $78-88$ & 2 & $6,2 \%$ \\
$\mathbf{4}$ & $89-99$ & 7 & $21,9 \%$ \\
$\mathbf{5}$ & $100-110$ & 5 & $15,7 \%$ \\
$\mathbf{6}$ & $111-121$ & 9 & $28,2 \%$ \\
$\mathbf{7}$ & $122-132$ & 4 & $12,5 \%$ \\
$\mathbf{8}$ & $133-143$ & 2 & $6,2 \%$ \\
& & 32 & 100 \\
\hline
\end{tabular}

\section{skor resiliensi...}

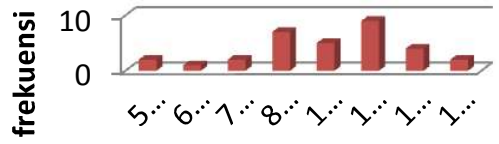

Gambar Distribusi Frekuensi Skor Resiliensi Keluarga

Tabel dan gambar menunjukkan bahwa frekuensi terbesar terdapat pada interval 111-121 yaitu 9 keluarga atau sebesar 28,2\%. Sedangkan frekuensi terkecil terdapat pada interval 67-77 yaitu sebanyak 1 keluarga atau 3,1\%.

Skor resiliensi keluarga juga dideskripsikan berdasarkan ukuran pemusatan dan penyebaran. Ukuran pemusatan dan penyebaran bertujuan menggambarkan karakteristik, ciri atau keadaan data hasil penelitian. Hasilnya dapat dilihat pada tabel

Skor resiliensi keluarga berdasarkan ukuran pemusatan dan penyebaran

\begin{tabular}{lc}
\hline Mean & $\mathbf{1 0 4 , 9 7}$ \\
& \\
\hline Median & 108,15 \\
\hline Modus & $56^{\mathrm{a}}$ \\
\hline Standar Deviasi & 20,382 \\
\hline Varians & 415,412 \\
\hline Range & 87 \\
\hline Nilai Maksimum & 143 \\
\hline Nlai Minimum & 56 \\
\hline Skor Total & 3359 \\
\hline
\end{tabular}

Dari tabel yang sudah dibuat dapat diketahui bahwa skor mean untuk resiliensi keluarga adalah adalah 104,97. Nilai maksimum empirik yang diperoleh adalah 143 dan nilai minimumnya adalah 56.

Dari hasil pengukuran resiliensi keluarga, telah didapat hasil sebagai berikut :

\section{Skor Resiliensi Keluarga Berdasarkan Mean, Median, Nilai Minimum, dan Nilai Maksimum}

\begin{tabular}{|c|c|c|c|c|}
\hline $\begin{array}{l}\mathbf{N} \\
\mathbf{0}\end{array}$ & Dimensi & Mean & Minimum & Maksimum \\
\hline 1. & Stressor & 13,3 & $\overline{0}$ & 31,7 \\
\hline 2. & Strain & 8,38 & 0 & 28,1 \\
\hline 3. & $\begin{array}{l}\text { dukungan kerabat dan } \\
\text { teman }\end{array}$ & 25,5 & 40 & 71 \\
\hline 4. & dukungan sosial & 45,12 & 19 & 33 \\
\hline 5. & ketahanan keluarga & 43,37 & 21 & 53 \\
\hline 6. & kemampuan coping & 16,71 & 11 & 20 \\
\hline 7. & distress & 4,06 & 0 & 33,6 \\
\hline
\end{tabular}

Dari data dapat kita ketahui bahwa dalam resiliensi keluarga, dimensi dukungan sosial memiliki mean tertinggi, yaitu sebesar 45,12. Diikuti selanjutnya oleh dimensi ketahanan keluarga, yaitu sebesar 43,47. Kemudian dimensi dukungan kerabat dan teman sebesar 25,5. Lalu dimensi selanjutnya adalah dimensi kemampuan coping yaitu dengan mean 16,71. Terakhir diikuti oleh faktor resiko keluarga dalam yaitu stressor, strain, distress yang masing-masing memiliki mean sebesar 13,3 lalu 8,38 dan 4,06.

Berdasarkan penelitian kuantitatif ada 4 (12\%) keluarga yang berada pada kategori stressor tinggi, $21(66 \%)$ keluarga yang berada pada kategori stressor medium, dan 7 (22\%) keluarga berada pada kategori stressor rendah. Berdasarkan penelitian kualitatif semua merasakan stressor berhubungan dengan diagnosis autis pada anak mereka. Jenis stressor yang dirasakan adalah stressor yang disebabkan oleh stressor utama dan perkembangan stressor utama sepanjang waktu, pembentukan pola keluarga yang baru, kematian salah satu pasangan, strategi coping yang digunakan sebelumnya yang membawa dampak, ketegangan yang telah terjadi sebelum stressor utama terjadi, dan transisi normatif yang terjadi pada keluarga besar.

Untuk strain, berdasarkan penelitian kuantitatif ada 4 (12,5\%) keluarga yang termasuk dalam kategori strain tinggi dan ada 28 (87,5\%) 
keluarga yang termasuk dalam kategori strain sedang. Tidak ada keluarga yang memiliki skor strain rendah. Berdasarkan penelitian kualitatif dari tiga keluarga yang diwawancara, semuanya mengalami strain. Diantaranya ialah, bertambah / sering terjadi konflik antara suami istri, masalah finansial keluarga yang menyebabkan ketegangan, hubungan yang renggang antara suami istri karena tuntutan pekerjaan, serta adanya konflik yang meningkat ketika mengatur anak-anak.

Berdasarkan penelitian kuantitatif didapat 4 $(12,5 \%)$ keluarga termasuk dalam keluarga yang memiliki dukungan kerabat dan teman yang tinggi, $25(78,1 \%)$ keluarga termasuk ke dalam kategori sedang, dan $3(9,4 \%)$ keluarga termasuk kedalam kategori memiliki dukungan kerabat dan teman yang rendah. Berdasarkan penelitian kualitatif dari ketiga keluarga yang diwawancara, satu keluarga mendapat dukungan yang berasal dari keluarga besar dan teman dapat berupa materi, ataupun mencarikan tempat terapi bagi anak mereka. Dua keluarga kurang mendapat dukungan dari keluarga besar dan teman, terkait dengan anak mereka yang autis.

Berdasarkan penelitian kuantitatif terdapat 4 keluarga $(12,5 \%)$ termasuk kedalam kategori memiliki dukungan sosial tinggi, 24 keluarga (75\%) termasuk dalam kategori memiliki dukungan sosial medium, dan 4 keluarga $(12,5 \%)$ termasuk dalam kategori memiliki dukungan sosial rendah. Berdasarkan penelitian kualitatif, dari tiga keluarga yang diwawancara, satu keluarga ikut serta dalam komunitas orangtua anak berkebutuhan khusus autisme dalam dunia maya (internet), satu keluarga tidak ikut dan tidak merasakan dukungan komunitas, satu keluarga ikut komunitas pengajian, tapi tidak terlibat aktif didalamnya. Ketiga keluarga mendapat dukungan sosial dari pihak yayasan.

Berdasarkan penelitian kuantitatif, terdapat 8 keluarga $(25 \%)$ yang termasuk ke dalam kategori tinggi, 15 keluarga $(46,9 \%)$ termasuk ke dalam

\section{Kesimpulan}

Berdasarkan hasil penelitian kuantitatif dapat disimpulkan bahwa resiliensi keluarga pada keluarga yang memiliki anak autis berada pada kategori medium. Hal ini dilihat dari dua faktor yang mempengaruhi resiliensi keluarga yaitu faktor resiko keluarga (stressor, strain, distress) dan faktor protektif keluarga (Relative and friend kategori sedang dan 9 keluarga $(28,1 \%)$ termasuk kedalam keluarga yang memiliki ketahanan keluarga rendah. Berdasarkan penelitian kualitatif dari tiga keluarga yang diwawancara, didapat satu keluarga tidak memiliki ketahanan keluarga yang baik, karena merasa kesepian dan sendiri, tidak memiliki komponen saling percaya dan komponen berkomitmen yang baik. Dua keluarga sudah memiliki ketiga komponen yaitu tantangan, saling percaya dan komitmen yang baik.

Berdasarkan penelitian kuantitatif terdapat 5 keluarga $(15,6 \%)$ yang memiliki coping-coherence tinggi, 4 keluarga (12,5\%) yang memiliki copingcoherence rendah dan 23 keluarga (71,9\%) yang memiliki coping-coherence sedang (medium). Berdasarkan penelitian kualitatif didapat bahwa satu keluarga belum dapat mengembangkan karakteristik coping-coherence yang baik, karena masih menyesali tiap hal yang terjadi di masa lalu dan belum bisa menerima kondisi anak sepenuhnya. Dua keluarga sudah memiliki karakteristik copingcoherence yang cukup baik. Meski kerap mengeluh dengan kondisi anak, kedua keluarga mampu menerima peristiwa hidup sebagai fakta kehidupan, dan mampu mendefinisikan masalah keluarga sebagai hal yang positif serta memiliki kepercayaan penuh pada Tuhan.

Berdasarkan hasil penelitian kuantitatif terdapat 28 keluarga $(87,5 \%)$ yang memiliki distress sedang dan terdapat 4 keluarga $(12,5 \%)$ yang memiliki distress tinggi. Tidak ada keluarga yang memiliki distress rendah. Berdasarkan penelitian kualitatif, ketiga keluarga memiliki kecenderungan distress. Terjadi kekerasan dalam verbal maupun nonverbal, terdapat masalah emosi yang tidak stabil dalam anggota keluarga dan terpisahnya suami istri dalam jangka waktu yang lama serta terjadinya perceraian mati dalam kehidupan keluarga.

support, social support, family hardiness, copingcoherence).

Resiliensi keluarga yang tergolong medium menunjukkan bahwa keluarga yang memiliki anak autis memiliki skor yang seimbang pada kategori medium antara faktor protektif dan faktor resiko. Keluarga merasakan stressor utama dan stressor lain dalam keluarga, memiliki masalah-masalah 
(konflik) sebelumnya yang belum dapat diselesaikan (strain), dan memiliki kecenderungan distress keluarga. Kecenderungan distress keluarga ini menyebabkan keluarga akan semakin sulit beradaptasi dan mencapai bonadaption, sehingga siklus akan kembali mengulang.

Disisi lain, keluarga memiliki faktor protektif yang berasal dari keluarga itu sendiri (family hardiness dan coping-coherence family), keluarga besar (relative) serta dukungan sosial yang berasal dari relasi, teman, dan komunitas. Keluarga merasakan ada sedikit dukungan yang diberikan dari keluarga besar dan dukungan dari teman, sedikit yang merasakan dukungan komunitas. Hampir semua keluarga memiliki coping-coherence dengan memiliki kepercayaan penuh pada Tuhan. Selain itu, keluarga memiliki family hardiness yang tergolong medium. Meskipun sudah mampu bekerja sama antar anggota keluarga, tetapi keluarga belum sepenuhnya dapat melihat permasalahan sebagai suatu hal yang positif, keluarga juga memiliki kecenderungan untuk diam dirumah dan tidak melakukan aktivitas diluar rumah bersama teman.

Berdasarkan kedua faktor tersebut, hal ini dapat mengindikasikan bahwa resiliensi keluarga yang memiliki anak autis tergolong dalam kategori medium karena sudah terjadi penyesuaian dan mengalami krisis, dan belum dapat mencapai bonadapation .

Dari penghitungan data kuantitatif terhadap subjek kualitatif yang dilakukan, dua keluarga memiliki resiliensi keluarga yang tergolong rendah dan satu keluarga yang tergolong medium. Hasil penelitian kualitatif menunjukkan bahwa ketiga keluarga yang memiliki anak autis merasakan stressor dan strain yang tinggi dalam kehidupan keluarga, sehingga mempengaruhi pola fungsi keluarga. Ketiga keluarga juga memiliki kecenderungan distress keluarga yang akan mengindikasikan keluarga mengalami maladaptasi. Masalah emosi yang dimiliki salah satu anggota keluarga yaitu anak autis membuat semakin sulitnya adaptasi keluarga. Terpisahnya suami dan istri dalam jangka waktu yang lama juga membuat keluarga akan semakin sulit beradaptasi.

Ketiga keluarga memiliki faktor protektif keluarga yang berbeda-beda. Dari berbagai faktor protektif keluarga yang dirasakan oleh keluarga dapat disimpulkan bahwa satu keluarga memiliki faktor protektif yang tergolong rendah dan dua keluarga memiliki faktor protektif yang tergolong medium. Hal ini berdasarkan faktor dukungan sosial yang dirasakan oleh keluarga dan faktor dari dalam keluarga itu sendiri. Dua keluarga mampu memiliki kerja sama yang cukup baik dan dapat berbagi tugas dalam mengasuh dan mendidik anak mereka yang autis. Satu keluarga tidak memiliki kerja sama antar anggota keluarga karena memutuskan menjadi orangtua tunggal bagi anak. Satu keluarga sudah mampu menerima keberadaan dan kondisi anak yang autis, satu keluarga belum serempak dalam hal penerimaan kondisi anak (ayah belum menerima, tapi ibu sudah menerima), dan satu keluarga belum dapat sepenuhnya menerima kondisi anak.

Semua masih terasa sulit, sehingga lebih banyak mengeluh ketika memperjuangkan pendidikan dan mengasuh anak. Ketiga keluarga meyakini bahwa akan lebih baik bila anak mereka diasuh dan dididik oleh keluarga inti tanpa bantuan keluarga besar ataupun pengasuh anak. Kecuali untuk bantuan finansial, keluarga berharap keluarga besar mau membantu.

Resiliensi keluarga perlu dilihat sebagai satu kesatuan yang utuh. Terutama dalam melihat berbagai peristiwa kehidupan yang terjadi, sehingga setiap keluarga yang memiliki anak autis dapat beresiliensi dengan baik. Setiap keluarga saling mendukung untuk akhirnya mampu beradaptasi dan memiliki tujuan yang sama untuk memberi yang terbaik baik anak yang berkebutuhan khusus autisme yang adalah anggota keluarga mereka.

Implikasi dari penelitian ini adalah keluarga, pemerhati autis, pedagog, pendidik, psikolog, terapis dapat melihat dimensi yang bisa dikembangkan untuk dapat membantu proses penyesuaian dan adaptasi keluarga yang memiliki anak autis. Proses adaptasi bukanlah hal yang mudah untuk dikerjakan dan membutuhkan jangka waktu yang panjang untuk prosesnya. 


\section{Daftar Pustaka}

Admin, Autism, Sebuah Gangguan Perilaku Pada Anak, h.1

(http://childrenautismclinic.wordpress.com/201 1/10/23/autism-sebuah-gangguan-perilakupada-anak/), diakses pada 28 November 2011

Andriyani. Studi Kritis Penerapan Teori-teori Belajar dan Pendidikan Agama Kristen (PAK) Bagi Anak Autisme Usia Dini 2-6 Tahun. Bandung: STT Baptis. 2008

Anggraeni, Resiliensi Pada Penyandang Tuna Daksa Pasca Kecelakaan (Depok: Universitas Gunadarma, 2008), diambil dari http://www.gunadarma.ac.id/library/articles/gra duate/psychology/2008/Artikel 10503144.pdf, pada 25 November 2011

Armeini, Anna. Analisis Data Penelitian Kuantitatif Dengan SPSS. Jakarta: Fakultas Ilmu Pendidikan Universitas Negeri Jakarta. 2009

Armeini, Anna \& Dyah Ratna. Statistika Inferensial Untuk penelitian Psikologi dan Pendidikan. Dilengkapi Analisis Data Dengan SPSS. Jakarta: Fakultas Ilmu Pendidikan Universitas Negeri Jakarta: 2009.

Autisme, h.1, 2011 (http://id.wikipedia.org/wiki/Autisme,) diakses pada 25 Juli 2011 pukul 13.32

Barona, Perhatian Pemerintah Terhadap Penderita Autis Masih Minim, h.1 (http://obrolanbisnis.com/perhatian-pemerintahterhadap-penderita-autis-masih-minim/), diakses pada 28 November 2011

Bayat, M. Evidence of resilience in families of children with autism. Journal of Intellectual Disability Research VOLUME 51 PART 9 pp 702-714 SEPTEMBER 2007

Bitsika, dkk. How is resilience associated with anxiety and depression? Analysis of factor score interactions within a homogeneous sample. Reprinted from the German Journal of Psychiatry · http://www.gjpsy.uni-goettingen.de · ISSN 1433-1055. 2003.

Brace, Heather. Lived Experience: Diverse Perspectives on Raising a Child with Autism. Florida: Department of Special Education College of Education University of South Florida. 2009
Bungin, Burhan. Penelitian Kualitatif. Cetakan ke3. Jakarta: Kencana Prenada Media Group. 2009

Creswell, John C. Research Design Pendekatan Kualitatif, Kuantitatif, dan Mixed. Edisi Ketiga. Yogyakarta: Pustaka Belajar. 2010

Creswell J, Clark VLP. Designing and Conducting Mixed Methods Research. United Kingdom: Sage Publication. 2007

Davidson, dkk. Psikologi Abnormal. Edisi ke 9. Jakarta: PT RajaGrafindo Persada. 2004

Desmita. Psikologi Perkembangan (Bandung: Remaja Rosdakarya. 2005

Diagnostic and Stattistical Manual of Mental Disorders. Fourth Edition. Washington DC: Published by the American Psychiatric Association. 2005

Dimyanti, Penanganan Anak Autis Minim, h.1 (http://www.jurnas.com/halaman/9/2011-11$\underline{05 / 188018}$ ), Jurnas Nasional, diakses pada 28 November 2011

Dwi Rahmawati, R. Pengaruh Iklim sekolah terhadap resiliensi siswa korban kekerasan (bullying) di sekolah dasar kelurahan pegangsaan Jakarta pusat. Jakarta: FIP UNJ 2009

Fakta Autisme, h. 1 (http://www.lspr.edu/csr/autismawareness/?page id=26), diakses pada 14 November 2011, pukul 15.11

Fritz, J, Childhood Cancer and Changes in Family Relationship and Functioning: What Are They and Where Does Support Fit in?. (Disertation: University of Michigan, 2005), 14 November 2011 pukul 15.00

Hanekom, Letche. Resilience in families with a child living with autism spectrum disorder. Africa: Nelson Mandela Metropolitan University. 2008.

Hildayani. Penanganan Anak Berkelainan (Anak dengan Kebutuhan Khusus). Jakarta: Universitas Terbuka. 2009. 
Heryanto. Identifikasi dan Asesmen Anak Autis, Yogyakarta: Pendidikan Luar Biasa Universitas Negeri Yogyakarta. 2009.

Jhonson and Hustings. Stress in UK Families Conducting Intensive Home-Based Behavioral Intervention for Their Young Child with Autism. Journal of Autism and Developmental Disorders, Vol. 31, No. 3, 2001

Judarwanto, Kenali Faktor Resiko Dan Gejala Autis Sejak Dini, h. 1 (http://kesehatan.kompasiana.com/ibudan-anak/2011/02/01/kenali-faktor-resiko-dangejala-autis-sejak-dini/), diakses pada 28 November 2011

Keluarga Tanpa Anak, Bisakah? h. 1, 2011 (http://kesehatan.kompasiana.com/ibu-dananak/2011/04/22/keluarga-tanpa-anak-bisakah/), diakses pada 24 oktober 2011 pukul 16.02

Khodijah, Wahyu. Resiliensi pada Siswa SMA yang Tidak Lulus Ujian Nasional. Jakarta: Fakultas Ilmu Pendidikan, Universitas Negeri Jakarta, 2010

Kuncono, Aplikasi Komputer Psikologi, Diktat Kuliah dan Panduan Praktikum, Jakarta: Fakultas Psikologi Universitas Persada Indonesia. 2004

Mackanzie, H. Reaching and Teaching the Child with Autism Spectrum Disorder Using Learning Preferences and Strengths. London and Philadelphia: Jessica Kingsley Publishers. 2008

Makalah Autis. 2009

Makna Kehadiran Anak, h.1 2011, (http://sabda.org/c3i/04/jul/2006/konseling_mak na kehadiran anak), diakses pada 24 oktober 2011, pukul 15.57

Marijani, L. Bunga Rampai Seputar Autis \& Permasalahannya. Jakarta: Putra Kembara Foundation. 2003

McCubin, H,I., Thompson, A.I., \& McCubbin, M. Family Measures: Stress, Coping, and Resiliency. Hawaii: Kamehameha Schools. 2001

Meadan, Halle, \& Ebata. Families With Children Who Have Autism Spectrum Disorders : Stress and Support. Vol. 77 No. 1. pp. 736. Jurnal ProQuest. 2010
Moleong. Metodologi Penelitian Kualitatif. Bandung: PT Remaja Rosdakarya. 2000

Mierau, L. Emerging Resilience In A Family Affected By Autism. University of Saskatchewan. 2008

Murti, Bisma. Desain Studi. Surakarta: Universitas Negeri Sebelas Maret. 2011.

MZW, "Tenaga Ahli Autisme Terbatas." Kompas, 15 Maret 2012

Netta. Resiliensi Pada Keluarga yang Memiliki Anak Kanker. Depok: Universitas Indonesia. 2011

Pamoedji. 200 Pertanyaan dan Jawaban seputar Autisme. Ciputat: Penerbit Hasanah. 2010

Pedoman Penyelesaian Studi. Jakarta: Fakultas Ilmu Pendidikan Universitas Negeri Jakarta: 2008

Penyandang Meningkat Delapan Kali Lipat, h. 1 (http://m.kompas.com/news/read/2011/05/04/21 480480/Penyandang.Meningkat.Delapan.Kali), diakses pada 14 November 2011, pukul 01.00

Perceraian Pada Keluarga Yang Mempunyai Anak Autistik, p.1 (http://www.kidaba.com/artikel/autis-autismautisme), diakses pada 14 November 2011 pukul 15.00

Perlindungan Anak, h.1 2011 http://yosuapenta.multiply.com/journal/item/18 ?\&show interstitial $=1 \& \mathrm{u}=\% 2 \mathrm{Fjournal} \% 2 \mathrm{Fitem}$ ), diakses pada 24 Oktober 2011

Poerwandari, K. Pendekatan Kualitatif untuk Penelitian Perilaku Manusia. Depok: LPSP3 Universitas Indonesia. 2009

Ratnadewi. Peran Orangtua Pada Terapi Biomedis Bagi Anak Autis. Depok: Universitas Gunadarma. 2009

Rotatori,Obiakor, Burkhardt. Autism and Developmental Disabilities: Current Practices and Issues. Volume 18. First Edition. UK: Emerald Group Publishing Limited. 2008 
Rynearson. Resilience and Intervention Beyond the Crisis. New York: Taylor \& Francis Group. 2006

Saifuddin Azwar. Penyusunan Skala Psikologi. Yogyakarta : Pustaka Belajar. 2009

Schopler, dkk. THE RESEARCH BASIS FOR AUTISM INTERVENTION. New York, Boston, Dordrecht, London, Moscow: Kluwer Academic Publishers. 2002

Seminar Tumbuh Kembang Anak. Sentuhan yang Membangunkan. Depok: Sekolah dan Terapi Kasih Mama. 26 Februari 2011

Stewart \& Cash. Interviewing. Principles and Practices. Twelfth Edition. Singapore: McGraw Hill. International Edition. 2008

Sutadi, dkk. Penatalaksanaan Holistik Autisme, Kongres Nasional Autisme Indonesia Pertama. Jakarta: Pusat Informasi dan Penerbitan Bagian Ilmu Penyakit Dalam Fakultas Kedokteran Universitas Indonesia. 2003

Sugiarmin Muhammad. Individu dengan Autisme. Bandung: Universitas Pendidikan Indonesia. 2010

Sugiyono. Metode Penelitian Pendidikan Pendekatan Kuantitatif, Kualitatif, dan R\&D. Bandung: Alfabeta. 2010

Usman, Husaini. Pengantar Statistika. Edisi Kedua. Jakarta: PT Bumi Aksara: 2006

Van der Walt. Resilience in Families with an Autistic Child. (South Africa: University of Stellenbosch. 2006

VanBreda, Adrian. Resilience Theory: A Literature Review, with special chapters on deployment resilience in military families \& resilience theory in social work. Pretoria, South Africa. 2001

Vliem, S. Adolescent Coping and Family Functioning in the Family of a Child with Autism. Michigan: The University of Michigan. 2009
Walsh, Froma. A Family Resilience Framework: Innovative Practice Applications. Family Relations; Apr2002, Vol. 51 Issue 2. 2002

Zager, Dianne. Autism Spectrum Disorders. Identification, Education, and Treatment. Third Edition. Mahwah, New Jersey, London: Lawrence Erlbaum Associates, Publishers. 2005 